\title{
Recent Developments and Applications of Photoconjugation Chemistry
}

\author{
Fan Xiao, Xiaoyun Zhang, and Xiaoguang Lei ${ }^{\star}$
}

\begin{abstract}
Understanding of biological systems has always been the general interest in chemical biology, and chemical modifications of biomolecules are often required to elucidate their functions and properties. There has thus been a rapid development of covalent chemistries for the modification of macromolecules. Among these strategies, photochemistry provides the advantage of using biocompatible light as an energy source to trigger bioconjugation reactions; this circumvents the use of toxic reagents (e.g. metal catalysts and chelating ligands). Light-induced chemistry can achieve precise spatial and temporal conjugation of biomolecules in their native environment.
\end{abstract}

Keywords: Bioorthogonal ligation · Chemical biology · Photoconjugation · Small molecule probe

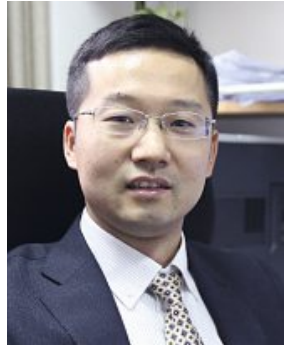

Prof. Xiaoguang Lei obtained his BS in chemistry from Peking University in 2001, and $\mathrm{PhD}$ in natural product synthesis and chemical biology with Prof. John. A. Porco from Boston University in 2006. He did a postdoc with Prof. Samuel J. Danishefsky at Columbia University from 2006 to 2008. In 2009, Prof. Lei returned to China, and started his independent research career as a Principal Investigator at the National Institute of Biological Sciences (NIBS) in Beijing. In early 2014, he moved to the College of Chemistry at Peking University. $\mathrm{He}$ is currently a full professor at PKU. The major research areas of Prof. Lei's laboratory are: chemical biology, natural product total synthesis, and drug discovery. He has received the 2018 David Ginsburg

\footnotetext{
${ }^{\star}$ Correspondence: Prof. X. Lei Department of Chemical Biology

College of Chemistry and Molecular Engineering Beijing National Laboratory for Molecular Sciences Key Laboratory of Bioorganic Chemistry and Molecular Engineering of Ministry of Education Synthetic and Functional Biomolecules Center and Peking-Tsinghua Center for Life Sciences Peking University, Beijing 100871, China E-mail: xglei@pku.edu.cn
}

Lectureship Award, the 2017 Tetrahedron Young Investigator Award, the 2017 Swiss Chemical Society Lectureship Award, the 2015 Chemical Society of Japan Distinguished Lectureship Award, and the 2013 ICBS Young Investigator Award.

\section{Introduction}

Biological systems are complex, a situation that hampers investigation to elucidate the functions of macromolecules. Chemical biologists have creatively developed many bio-compatible chemical reactions that can be utilized in living systems. These bio-compatible reactions - also known as bioorthogonal reactions - include well-known examples like azide-alkyne cycloaddition and Diels-Alder reactions, etc. An ideal bioorthogonal reaction should possess the following features: 1) the reaction must be selective to the biomolecules of interest, without interfering with other cellular processes; 2) the reaction can be operated under aqueous conditions, as this is the physiological environment; 3) the reagents and the products of the reaction should be relatively stable and non-toxic to the cells; 4) the reaction should exhibit relatively fast kinetics to capture cellular events. In addition to fulfilling each of these fundamental pre-requisites, lightinduced chemistries offer the ability for precise spatial and temporal manipulation of bioorthogonal reactions. The past two decades have witnessed the development of a number of remarkable new photoconjugation chemistries. These reactions have been widely applied in chemical biology studies. In this short review, we highlight the recent developments and applications of photoconjugation chemistry.

\section{Photo-induced Bioorthogonal Reactions}

\subsection{Photo-induced Azide-Alkyne Cycloaddition}

Copper(I)-catalyzed azide-alkyne cycloaddition was first reported by Sharpless and Meldal in 2001. This reaction has been widely used in materials studies owing to its mild reaction conditions. However, as copper(I) is toxic, this reaction is not compatible with biological systems. In 2004, Bertozzi and coworkers developed strain-promoted azide-alkyne cycloaddition (SPAAC), in which cyclooctyne is used as the strained alkyne that can undergo 1,3-dipolar cycloaddition with azide in the absence of a catalyst (Scheme 1). ${ }^{[1]}$ They then demonstrated the robustness of this reaction by introducing cyclooctyne to $\mathrm{CHO}$ cells containing $\mathrm{N}$-azidoacetylmannosamin. ${ }^{[2]}$ In 2009, cyclopropenone was developed by the Popik group as a masked cyclooctyne. ${ }^{[3]}$ Under the irradiation of light, cyclopropenone undergoes decarbonylation to generate cyclooctyne in situ, and subsequently reacts with azide in $\mathrm{CHO}$ cells.

In 2017, the Spitale group utilized this photo-induced SPAAC to analyze the expression of mRNA in HeLa cells (Scheme 2). ${ }^{[4]}$ They initially introduced $2^{\prime}$-azidoadenosine $\left(2^{\prime} \mathrm{N}_{3}-\mathrm{A}\right)$ to the cell culture medium, so $2^{\prime} \mathrm{N}_{3}-\mathrm{A}$ would be incorporated into RNA during transcription. Oxo-dibenzocycloctyne (ODIBO) was then added to the culture medium and allowed to diffuse into the cells, followed by irradiation at $350 \mathrm{~nm}$ which generated cyclooctyne in situ and underwent SPAAC with the 2 ' $\mathrm{N}_{3}$-A present in RNA. This photo-induced SPAAC 


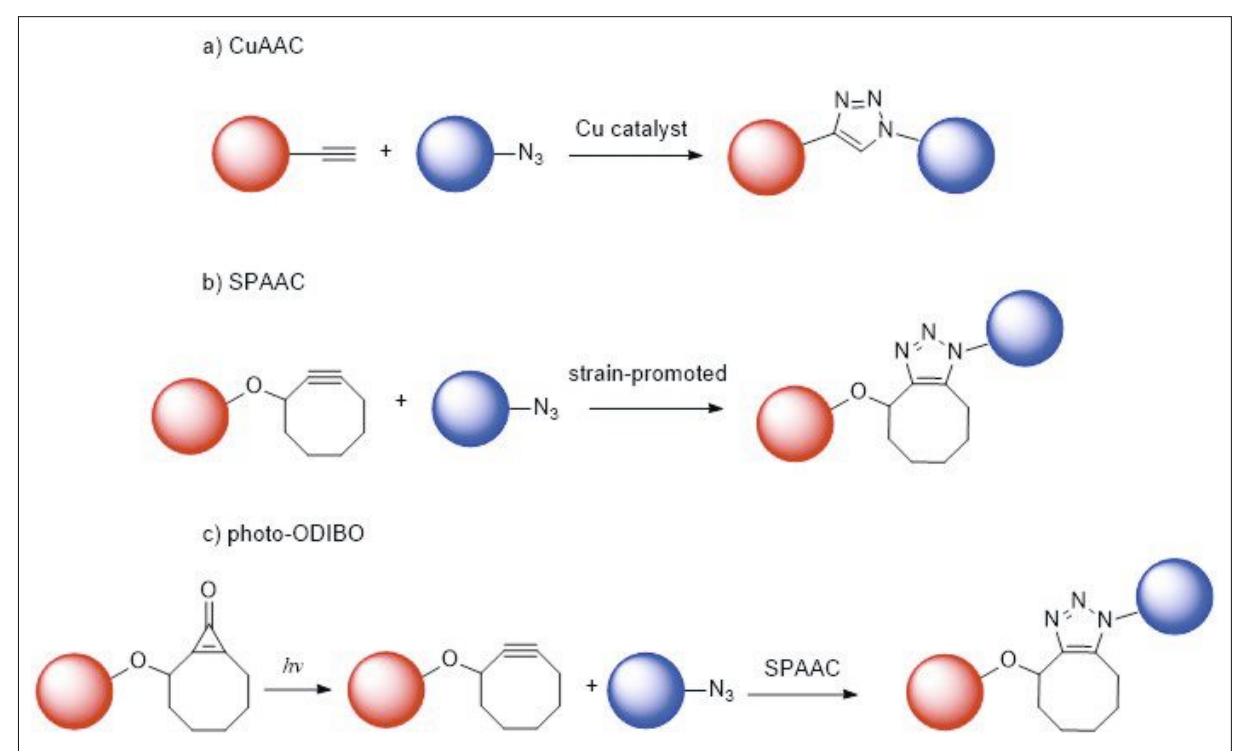

Scheme 1. Development of azide-alkyne cycloaddition.

strategy facilitated fluorescent imaging of cellular RNA. However, this methodology is limited to the tissue level because of the poor penetration of visible light. To tackle this limitation, the Popik group utilized near infra-red (NIR) radiation to trigger photo-induced SPAAC. ${ }^{[5]}$ Additionally, several alternative strategies for photo-induced azide-alkyne cycloaddition have been reported. In 2011, Bowman and co-workers used photoinitiators (e.g. Irgacure, $\mathrm{TiO}_{2}$, etc.) to reduce $\mathrm{Cu}$ (II) to $\mathrm{Cu}$ (I) in situ and subsequently promote azide-alkyne cycloaddition. ${ }^{[6]}$ Devaraj and co-workers achieved photoreduction of $\mathrm{Cu}$ (II) by $\mathrm{Ru}(\mathrm{II})$ in 2016. ${ }^{\text {[7] }}$ However, such methods for photo-reduction of $\mathrm{Cu}$ (II) have not been applied to study tissues because of the toxicity of $\mathrm{Cu}(\mathrm{I})$ and the low penetration of visible light. ${ }^{[8]}$

\subsection{Photo-induced Tetrazole Ligation}

Tetrazole-alkene cycloaddition was first reported by Huisgen and Sustmann in 1967. [9] They discovered that 2,5-diphenyl tetrazole could be converted into 2,5-diphenyl nitrile imine under thermal conditions with the loss of an $\mathrm{N}_{2}$ molecule during the process. The reactive 2,5-diphenyl nitrile imine would then undergo spontaneous 1,3-dipolar cycloaddition with the alkene to give fluorescent pyrazolinetype products. For a long time, the major application of this chemistry was in the synthesis of heterocyclic compounds and organic polymers. ${ }^{[10]}$ It was not until 2008 when Lin and co-workers reinvestigated this remarkable cycloaddition that it was applied to develop a fluorescent probe (Scheme 3); [11] in their work, a Z-domain protein was initially genetically mutated to encode an $O$-allyl-tyrosine residue at the $7^{\text {th }}$ position, and this was expressed in E. Coli prior to incubation with tetrazole. Upon UV irradiation (302 nm) for 10 minutes, the photo-induced tetrazolealkene cycloaddition afforded the fluorescent protein, which could be successfully detected.

Alternatively, NHS-tetrazole can be attached to a lysine in lysozyme, followed by photolysis of tetrazole and 1,3-dipolar cycloaddition with alkene (Scheme 4). [12] In 2010, the same group applied this chemistry in mammalian cells where an alkene-containing amino acid, homoallylglycine (HAG), was first incorporated into proteins with high efficiency (up to $85 \%$ ).[13] Notably, the proteins with incorporated HAG preserved their original structures and functions. Subsequently, the fluorophore-substituted tetrazole reacts with alkene to facilitate the visualization of newly translated proteins.

Photo-induced tetrazole ligation is not limited to protein labelling, it has also been applied to control the secondary structures of peptides. The Lin group reported the synthesis of stapled peptide helices within a linear peptide using photoinduced tetrazole ligation (Scheme 5). ${ }^{[14]}$ The newly formed macrocycle would restrain the conformation of the peptide into helices. In 2016, $\mathrm{Luo}^{[15]}$ and Yao ${ }^{[16]}$ independently reported the potential reactivity of tetrazole for carboxylic acids. The Luo group developed a novel protein labelling method to carboxylic acid based on tetrazole. Further investigations of the photo-induced tetrazole-alkene cycloaddition showed that the reactive 2,5-diphenyl nitrile imine intermediate could react with cysteine or be quenched by water; this problem can be overcome by modification of an $N$-Boc-pyrrole-substituted tetrazole (Scheme 6). ${ }^{[17]}$ UV light at $302 \mathrm{~nm}$ may cause photo-damage of cells, but this issue can be reduced by changing the UV wavelength to $365 \mathrm{~nm}$.

\subsection{Photo-induced Ligation Using Naphthoquinone Methide}

Photo-induced dehydration of 3-hydroxy-2-naphthalenemethanol (NQMP) in situ generates $o$-naphthoquinone me-

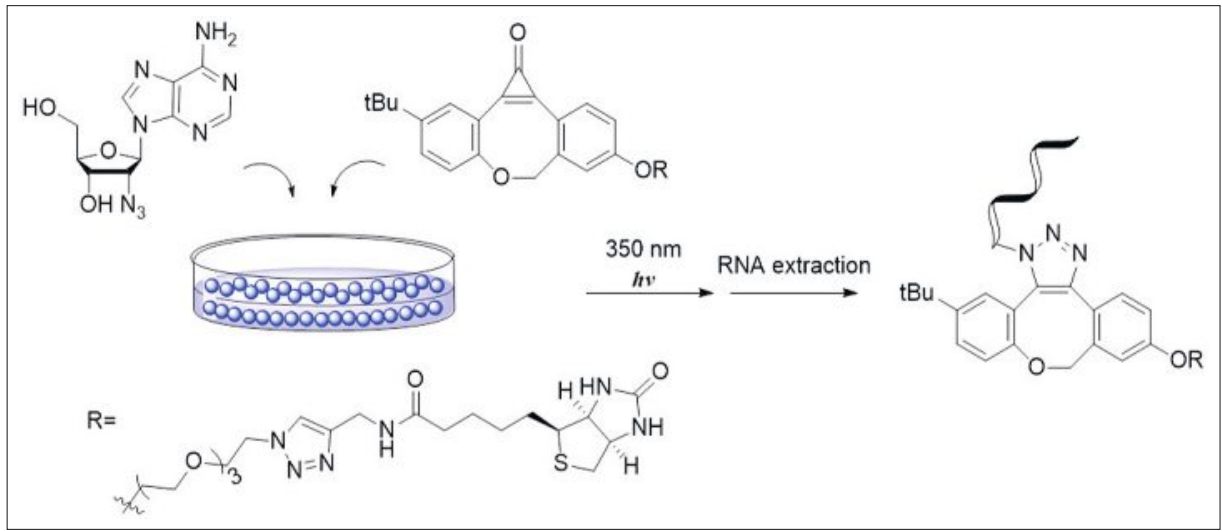

Scheme 2. Application of photo-induced azide-alkyne cycloaddition for RNA studies.

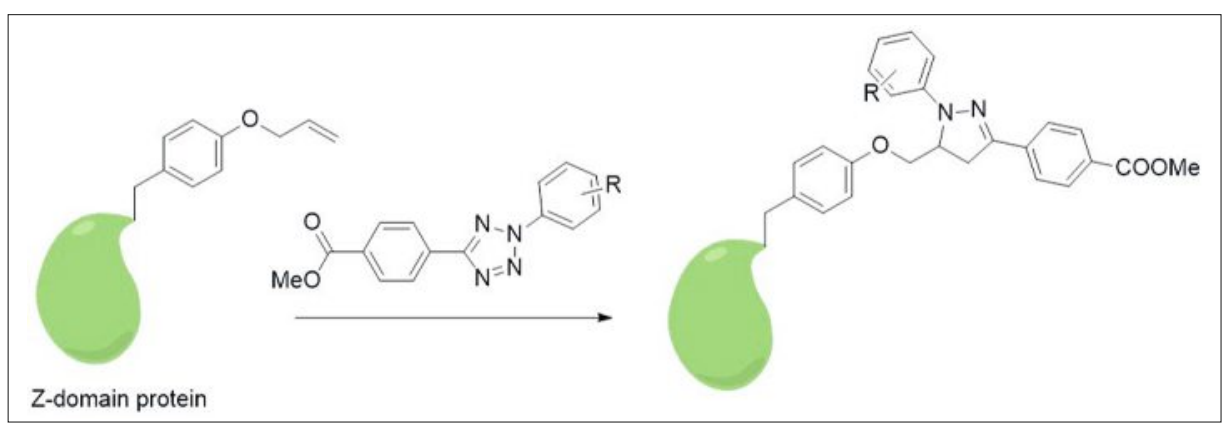

Scheme 3. Protein labelling using photo-induced tetrazole ligation. 


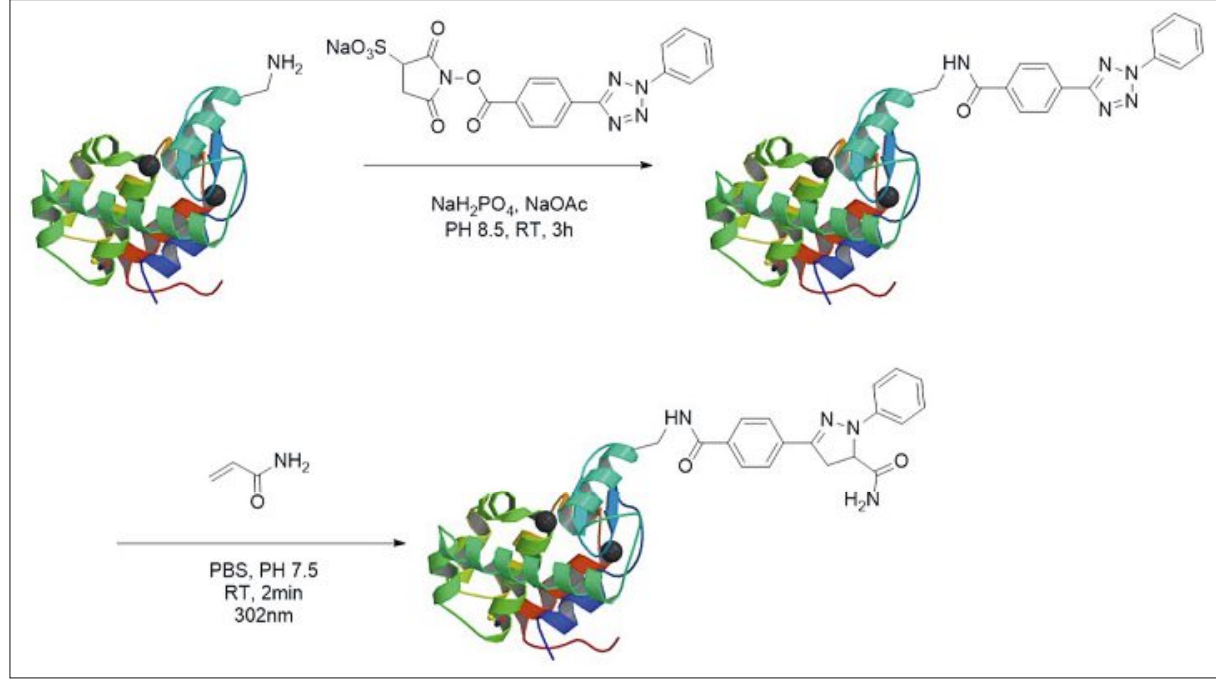

Scheme 4. Introduction of 2,5-diphenyltetrazole into lysozyme via acylation.

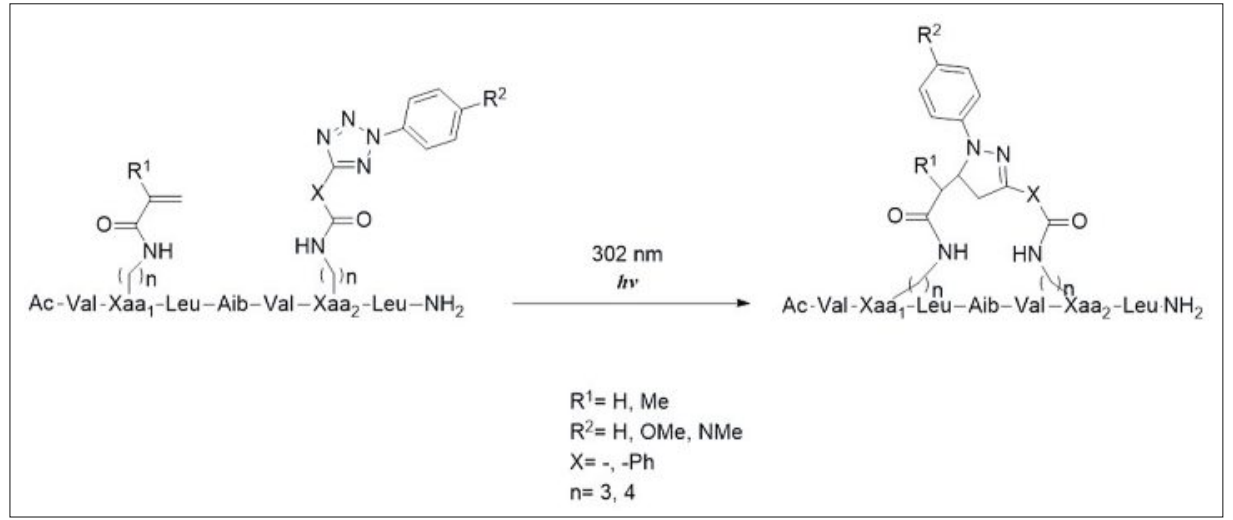

Scheme 5. Construction of the stapled peptide through photo-induced tetrazole-alkene reaction.

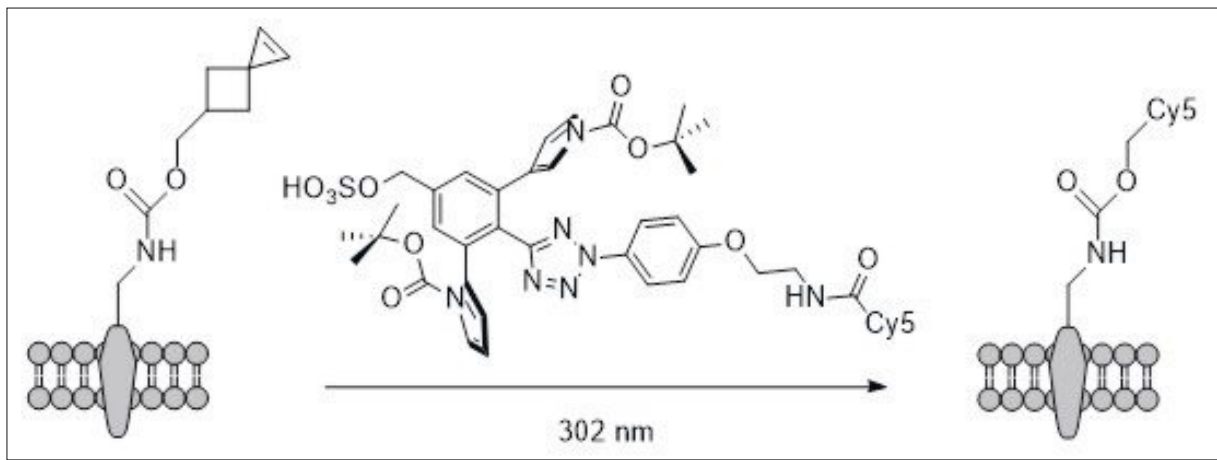

Scheme 6 . The specific reactivity of N-BOC-pyrrole substituted tetrazole for alkenes.

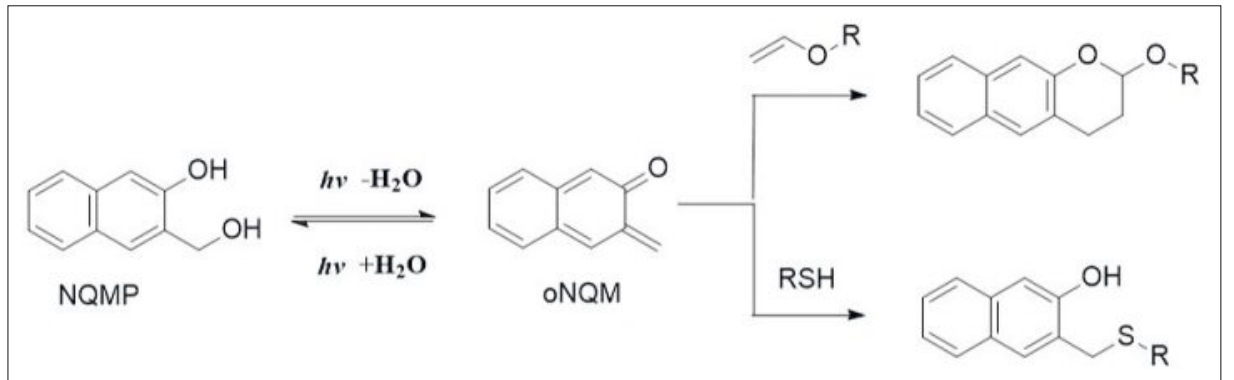

Scheme 7. [4+2]-hetero Diels-Alder cycloaddition using NQMP.

thides (oNQMs). Reactive intermediate oNQMs can be quenched by water or can be attacked by nucleophiles like ni- trogen, oxygen, or sulfur. ${ }^{[18]}$ For a long period of time, NQMP was mainly used as an alkylating agent of DNA, owing to the electrophilic nature of oNQMs. ${ }^{[19]}$ In 2011, Popik and co-workers developed alkene-oNQMs cycloaddition via a [4+2]-hetero-Diels-Alder cycloaddition process, ${ }^{[20]}$ and this has been further applied in the synthesis of functional materials ${ }^{[20]}$ and polymers. ${ }^{[21]}$ However, the reaction rate of this cycloaddition $(k=$ 4- $\left.6 \times 10^{4} \mathrm{M}^{-1} \mathrm{~S}^{-1}\right)$ is slower than thiol addition $\left(k=2.2 \times 10^{5} \mathrm{M}^{-1} \mathrm{~s}^{-1}\right),{ }^{[22]}$ and the low bioorthogonality of this cycloaddition has hampered its further application in physiological conditions. In 2014, Popik and coworkers reported photo-induced cysteine modification through thiol addition to oNQMs (Scheme 7). [22]

\subsection{Photo-induced Ligation Using Azirine and Alkene}

Azirine-alkene cycloaddition was first reported by Smolanoff and co-workers in 1971.[23] Under UV irradiation, the azirine was converted into nitrile ylides that subsequently underwent cycloaddition with electron-deficient olefins to afford the pyrroline ring. Lin and co-workers applied this chemistry to bioorthogonal reactions in lysozymes (Scheme 8). ${ }^{[24]}$ The lysozymes were initially modified with an azirine-containing succinimide ester. This labelling gave a mixture of mono-acylated $(44 \%)$, di-acylated $(23 \%)$, and tri-acylated $(7 \%)$ products. This mixture was then subjected to excess dimethyl fumarate, which makes the conversion from lyso-Azi to lyso-Pyr in $80 \%$ yield.

\subsection{Photo-induced Thiol-ene \\ Reactions}

The classic thiol-alkene (thiol-ene) reaction was first discovered a century ago. ${ }^{[25]}$ Under UV radiation, thiol would be converted into a thiyl radical that can further-react with an alkene. This chemistry was then applied in polymer synthesis. ${ }^{[26]}$ If the free thiols of cysteine on a protein surface are converted into thiyl radicals, the reaction would be nonselective and lead to the attachment of multiple alkene fluorophores onto a single protein. An alternative is to incorporate an unnatural amino acid containing alkene into the protein. In 2012, the Chen group successfully incorporated a non-canonical amino acid alkenyl-pyrrolysine into a protein, which was then reacted with thiyl radical under UV irradiation to achieve further labelling (Scheme 9). ${ }^{[27]}$ However, the broad application of this methodology has been limited due to the poor incorporation efficiency of the unnatural amino acid.

Another application of the thiol-ene reaction is for peptide stapling. The Chou group reported the synthesis of macrocyclization of peptides using the thiol-ene reaction. ${ }^{[28]}$ The stapled peptide shows high alpha helicity that successfully blocks the 


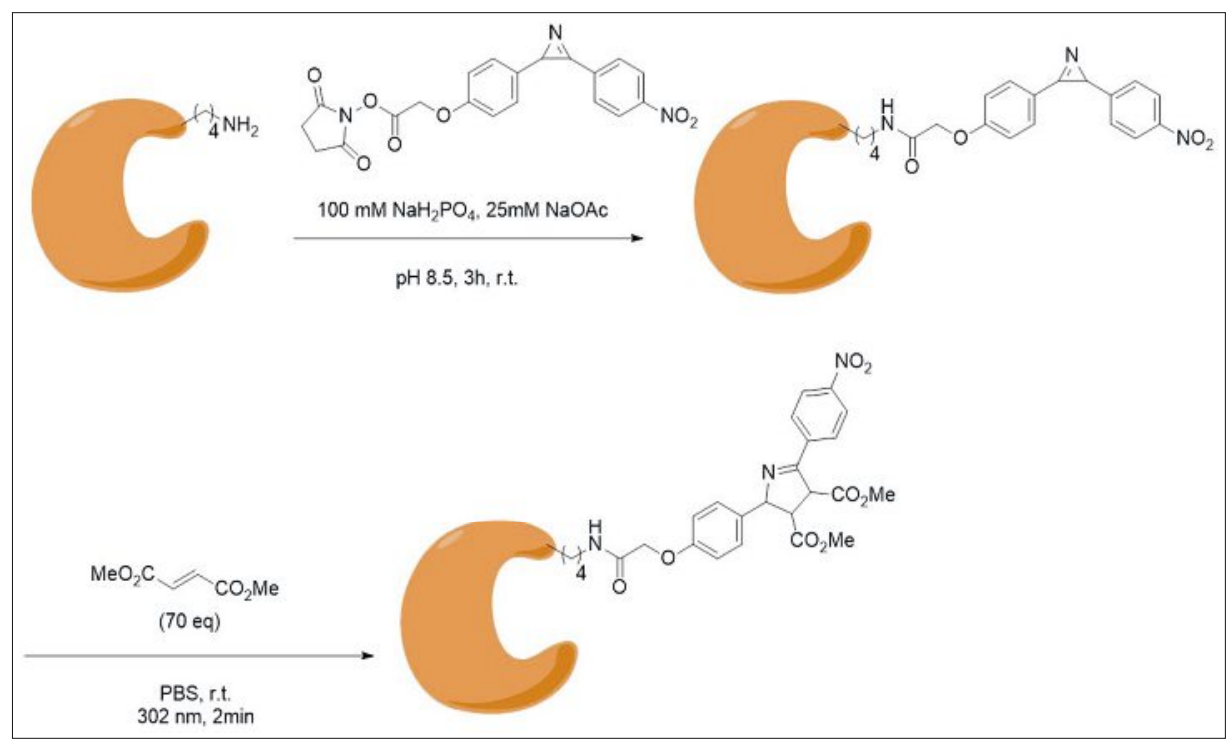

Scheme 8. Modification of the azirine-containing lysozyme by dimethyl fumarate.

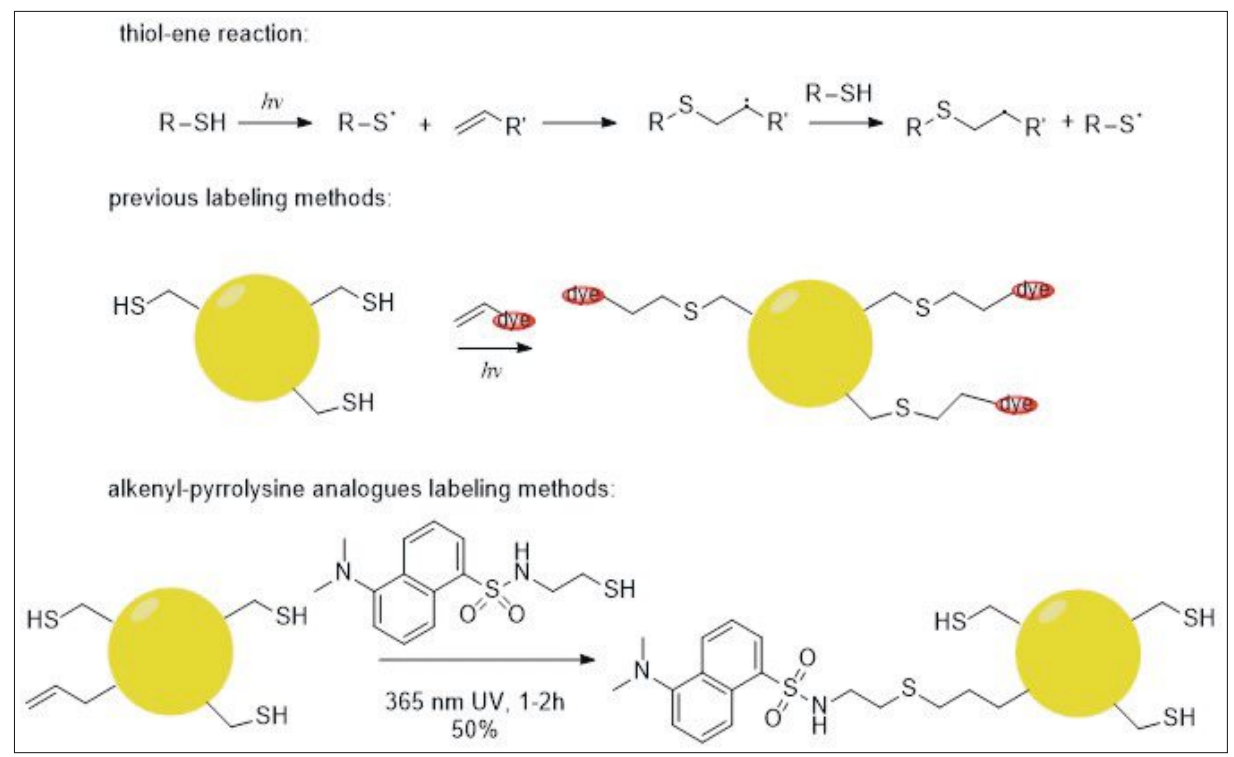

Scheme 9. Protein labelling with the thiol-ene reaction.

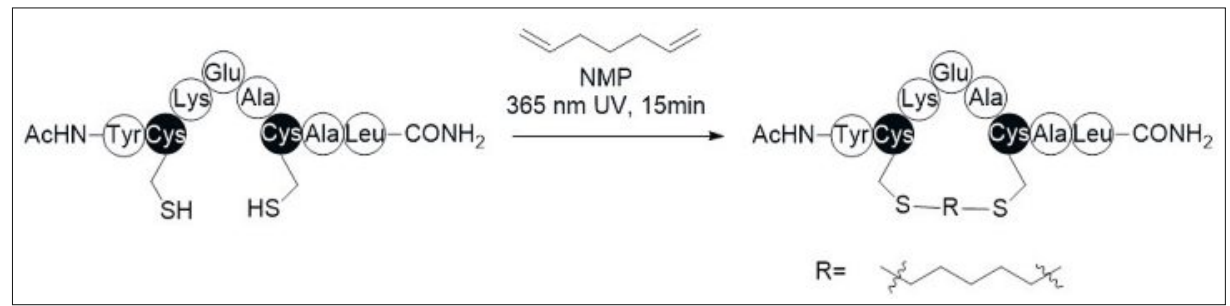

Scheme 10. Peptide stapling based on the thiol-ene reaction.

p53-MDM2 interaction and induces apoptosis in colorectal carcinoma HCT-116 cells (Scheme 10).

\subsection{Photo-induced Thiol-yne Reactions}

The thiol-yne reaction was first discovered by Jones in 1949. [29] Compared with the thiol-ene reaction, the thiol-yne reaction contains two steps (Scheme 11). A thiol group is UV irradiated $(254-470 \mathrm{~nm})$ to generate a thiyl radical; this then reacts with an alkyne to form an intermediate vinyl thio-ether through anti-Markovnikov regioselective addition. Subsequently, the intermediate undergoes a second thiyl radical addition to form a dithioether.

For many years, the thiol-yne reaction had been widely used in synthesizing materials or polymers. ${ }^{[30]}$ Inspired by progress in protein modification via the thiol-ene reaction, ${ }^{[31]}$ in 2011 , the Dondoni group reported a protein modification method using a thiol-yne reac- tion (Scheme 12).[32] Glucose-substituted alkyne and fluorophore-substituted thiol were respectively incubated with bovine serum albumin (BSA), which achieved fluoro-labelling and glycosylation at the same cysteine. However, this method cannot selectively modify a specified site on a protein that contains more than one cysteine residue.

To facilitate the modification of a single selected cysteine residue, the Guo group introduced an alkyne containing non-canonical amino acid into the HdeA protein, which under irradiation at $365 \mathrm{~nm}$ could then react with $N, N^{\prime}$-bis(dansyl) cystamine (Scheme 13). ${ }^{[33]}$ Their further investigations led to the discovery that the modified HdeA protein can suppress the aggregation of the SurA protein, and there is a study reporting that WT type HdeA possesses the same function, combined findings which together verify that incorporating such modifications of HdeA protein may not affect protein function. Other stapled peptide applications that use the thiol-yne reaction have also been reported.[27,34] In 2016, the Li group reported that with alkyne- and cysteinecontaining linear peptides they could form helical peptides via a thiol-yne reaction under UV irradiation $(365 \mathrm{~nm}) .{ }^{[35]}$ Estrogen receptors (ER) are a subfamily of nuclear receptors (NR). They synthesized a stapled peptide which mimic the box motif of NR. This stapled peptide can target the ER-coactivator binding region, which can be used as antagonists of ER.

\section{Covalent Bio-photoconjugation with Photo-activatable Small Molecule Probes}

\subsection{Background}

Elucidation of the interaction between macromolecules and the corresponding binding substrates is essential for the design of small molecule inhibitors. ${ }^{[36}$ However, for the weak and dynamic interaction between the macromolecules and the substrates, it can be difficult to capture the interaction and thus investigate the biomolecules involved in the native environment. Westheimer and co-workers reported the strategy using photoactivatable labelling[37] in which the key aspect of their method was to design a photoactivatable probe using the following three steps: 1) choosing a selective ligand that binds with the target macromolecule; 2) introducing a photo-reactive group for the covalent binding of the ligand to the target macromolecule upon triggering by light irradiation; 3) preparing a reporter tag that allows for the detection of the probe. ${ }^{[38]}$ Here, we discuss the most widely used photo-induced reactive groups: benzo- 


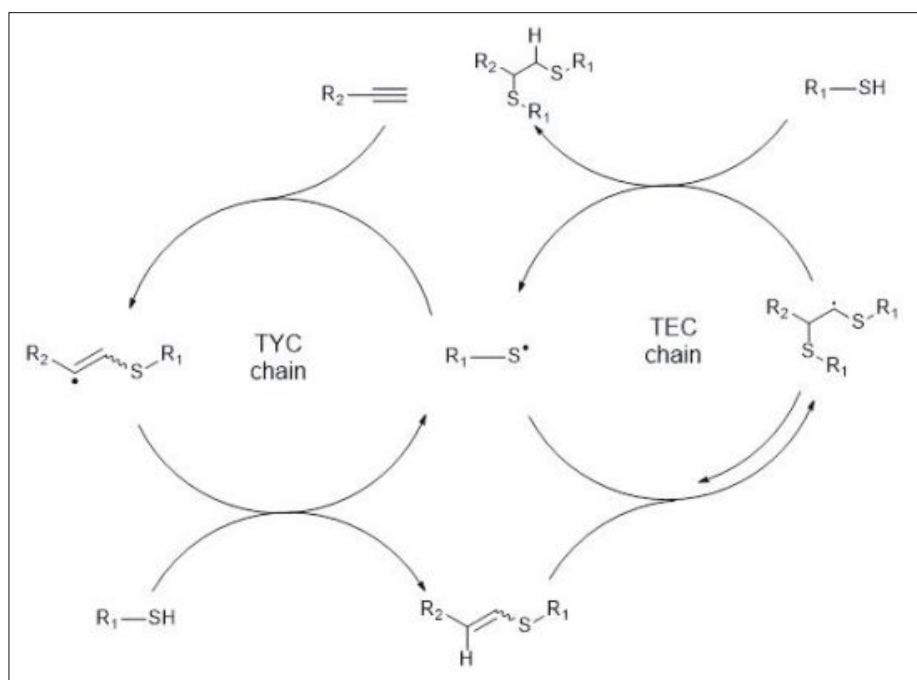

Scheme 11. Mechanism of the thiol-yne reaction.

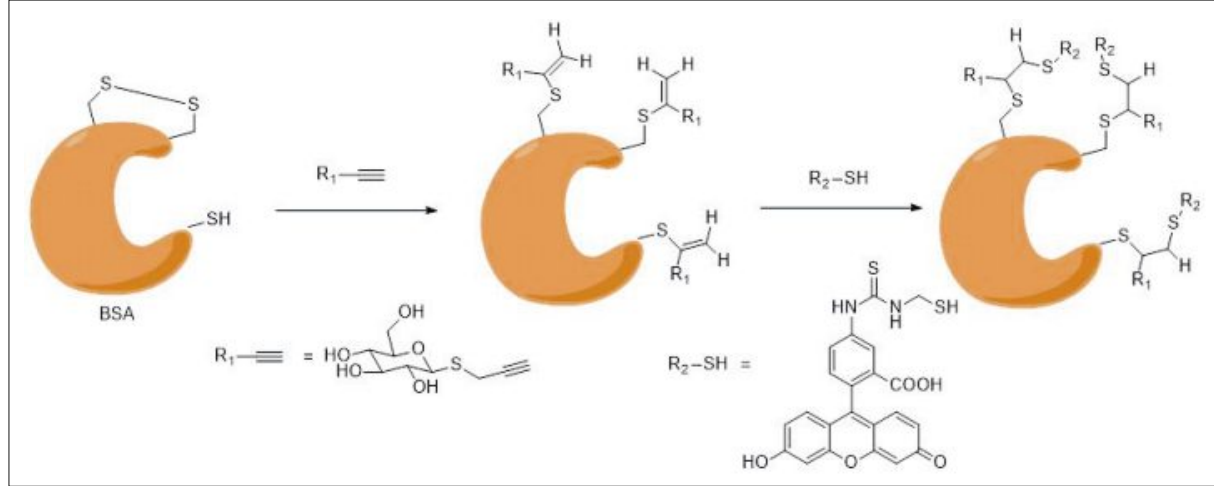

Scheme 12. Direct protein modification via the thiol-yne reaction.

Scheme 13. Selective protein modification via the thiol-yne reaction.
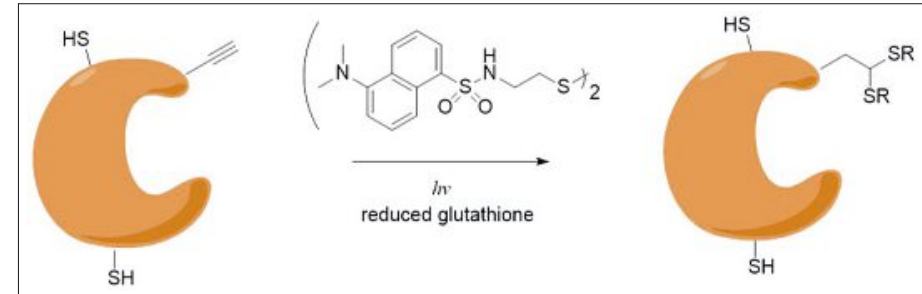

Fig. 1.

Photoactivatable labelling and photoactivatable groups.

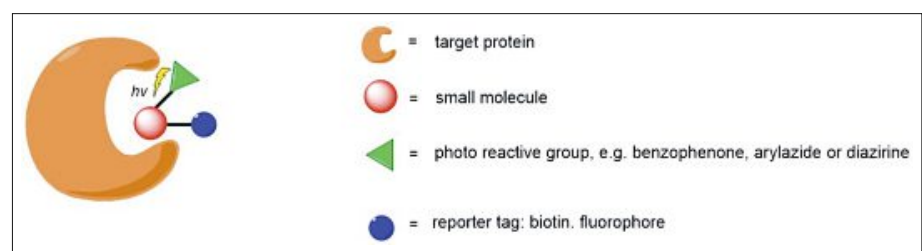

phenones, arylazides, and diazirines ${ }^{[39]}$ (Fig. 1)

Under 350-365 nm UV light, benzophenone will produce a di-radical species that can form a covalent bond with target macromolecules through selective binding of a ligand (Scheme 14). The relatively long wavelength of the activation photon allows this method to be conducted within cultured cells. Moreover, the syntheses for a large library of benzophenones derivatives have been well-established in previous literatures, and a large number of benzophenone-based building blocks are commercially available. However, a benzophenone usually requires a long photoactivation time, which can lead to phototoxicity of cells. Additionally, the large size of benzophenone may affect the original bioactivity of the modified ligand and/or alter its binding affinity for a target macromolecule.

Arylazide derivatives are stable in the dark and become highly reactive after activation by ultraviolet light (Scheme 15). The arylazide produces an active nitrene intermediate with the release of a nitrogen molecule (non-toxic) as the by-product. The nitrene then undergoes intramolecular dearomatized cyclization to give benzazirine or ring expansion to yield 1 , 2-azacycloheptatetraene.

Similar to arylazides, diazirines are stable under physiological conditions and can be activated by UV light from $350 \mathrm{~nm}$ to $380 \mathrm{~nm}$; nitrogen is released to give a reactive carbene species (Scheme 16). The relatively long wavelength of the light can reduce photo-damage to the cells. In addition, diazirine itself is small in comparison with benzophenone or arylazide, which can result in less pronounced effects on the structure/function of the target macromolecules after the chemical attachment. However, diazirines are less accessible owing to long and complex synthesis routes. Nonetheless, diazirines are more commonly used than the other two types of probes. Previous investigations have suggested that diazirine and diazo can transform back-and-forth under irradiation; ${ }^{[40]}$ there have also been studies that confirmed the formation of a carbene intermediate chemically ${ }^{[41]}$ and spectroscopically. ${ }^{[42]}$

\subsection{Ligand-Protein Interaction \\ 3.2.1 Bile Acids}

Bile acids (BAs) are essential metabolites that are synthesized in the liver from cholesterol and that are subsequently modified in the gut by microbiota. Not only do they help with dietary lipid digestion, bile acids can also regulate the metabolism of lipid and glucose and can influence gut microbiota composition. BA receptors are broadly expressed in diverse tissues, where they participate in a wide range of downstream signaling pathways. ${ }^{[43]} \mathrm{By}$ activating ${ }^{[44]}$ or inhibiting ${ }^{[45]}$ these receptors, BAs can regulate numerous physiological processes. Consistent with their strong associations with numerous signaling processes, disordered BA metabolism is associated with diverse human diseases. ${ }^{[46]}$ In the past 20 years, the nuclear farnesoid $\mathrm{X}$-receptor (FXR) and the plasma membrane bound $G$ protein-coupled receptor 5 (TGR5) have been well-characterized as BA receptors. ${ }^{[47]}$ Many processes are regulated by FXR and TGR5, and these are now regarded as therapeutic targets. To date, many agonists of FXR and TGR5 have entered clinical trials, ${ }^{[48]}$ yet it remains unclear if there are unknown receptors for BAs. To address this question, Lei and co-workers utilized quantitative chemical proteomic technologies and activity-based protein profiling to explore BA-interacting proteins (Scheme 17). ${ }^{[49]}$ To obtain reliable data from parallel experiments, they designed three types of clickable and photoreactive $\mathrm{BA}$ probes, as it is known that the site of a photo-reactive probe can influence its interaction with a protein. They identified > 600 potential BA-interacting proteins, among which were known receptors, transporters, and biosynthetic enzymes 


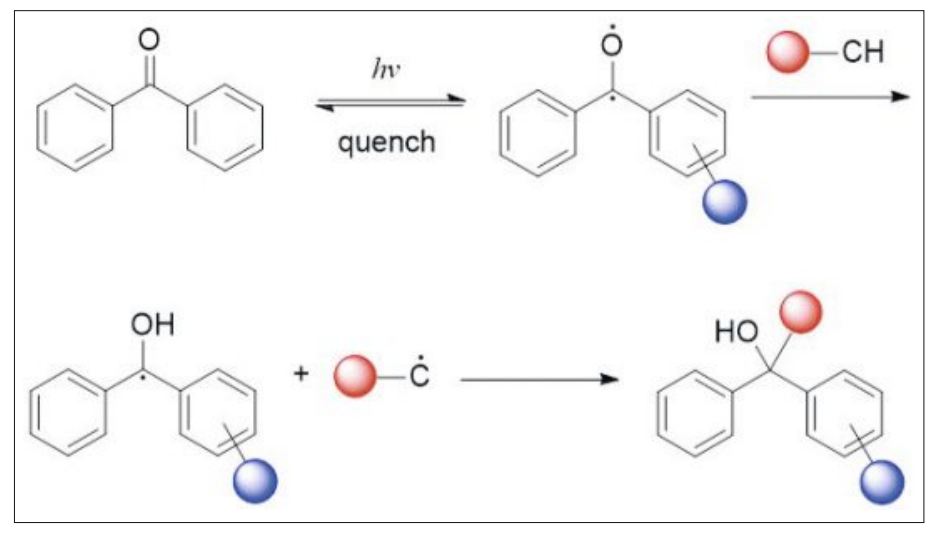

Scheme 14. Photoactivatable benzophenone.

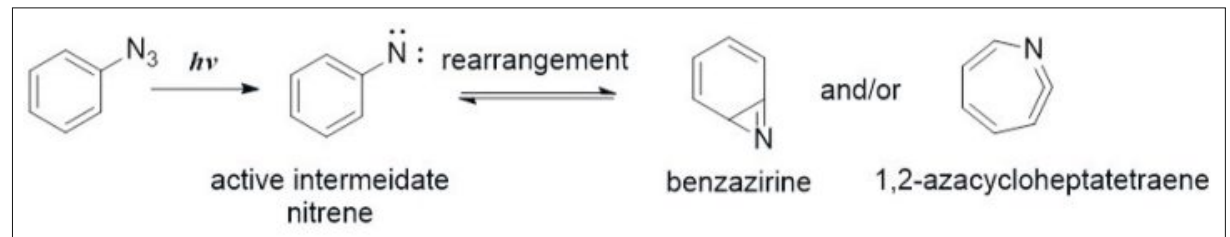

Scheme 15. Photoactivatable aryl azide.

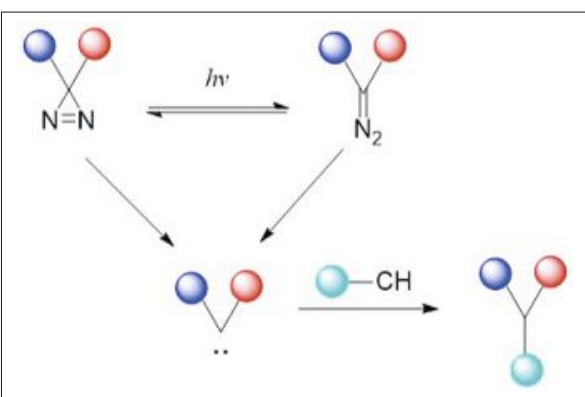

Scheme 16. Photoactivatable diazirine.

for BA, including a carnitine palmitoyl transferase 1A (CPT1A), ${ }^{[50]}$ phospholipase D (PLD), [51] ADP-dependent glucokinase (ADPGK), ${ }^{[52]}$ etc. This approach also led to the discovery of several novel BA-interacting proteins such as CPT1A, ADPGK, and catechol-O-methyltransferase (COMT) which were subsequently validated.

\subsubsection{Polypharmacology}

Many pharmaceutical agents show polypharmacology - they act on multiple targets or disease pathways. Notable ex- amples of this are the nonsteroidal antiinflammatory drugs (NSAIDs), ${ }^{[53]}$ certain immunomodulatory drugs, ${ }^{[54]}$ and opioids. ${ }^{[55]}$ NSAIDs are used to suppress inflammation, pain, fever, and as potential treatments for cancer and Alzheimer's disease. Elucidating the global interactions between a given molecule and the proteome is crucial for predicting polypharmacology. In 2018, Woo and coworkers developed a platform which they termed small molecule interactome mapping by photoactivatable labelling (SIM-PAL), and they used it to characterize the NSAID interactome (Fig. 2). ${ }^{[56]}$ There have been reports that the activity of the enzymes cyclooxygenase- 1 and -2 (COX-1, COX-2, respectively) ${ }^{[57]}$ and the signaling pathway of nuclear factor- $\kappa \mathrm{B}$ $(\mathrm{NF}-\kappa \mathrm{B})^{[58]}$ can be inhibited by NSAID. They used NSAID as a model as they developed the SIM-PAL method. They designed photo-reactive probes based on three NSAIDs: naproxen, celecoxib, and indomethacin. The inhibition activity of the probe for COX-2 in vitro was similar to that of the parent molecule, and docking studies also suggested that the binding region of the photo-reactive probe overlapped with the region of the parent molecules, showing that their photo-reactive probes can sometimes mimic the properties of their parent molecules. Jurkat cells and K562 cells were incubated with each of the three photo-reactive probes, followed by cell lysis, protein enrichment, and analysis using mass spectrometry (MS). This approach identified many putative NSAIDS-interacting proteins, including COX-2. To further increase the confidence of data, isotopic probes were used to detect low abundance proteins and to decrease the abundance of unmodified proteins. ${ }^{[59]}$

\subsection{Lipid-Protein Interaction}

Compared to protein-protein interactions, it remains challenging to elucidate lipid-protein interactions. ${ }^{[60]}$ However, lipoproteins are not only fundamental components of biological membranes, they also participate in numerous biological processes including cell signaling, transcriptional regulation, and protein trafficking, among others. Traditional methods used to investigate lipid-protein interactions include X-ray crystallography, NMR, and atomic force microscopy (AFM). Although all of these methods are powerful, applying these methods to investigate lipid-protein interactions normally requires the targeted macromolecules to be in a denatured state, which often results in the experimental results lacking accuracy. The emergence of photoactivatable labelling provides an attractive alternative approach for investigating lipid-protein interactions by utilizing lipid probes to capture interacting proteins in live cells.

\subsubsection{The Cell Membrane}

The cell membrane is a dynamic assembly formed of lipids and proteins, and the fusion process between vesicles from donor membranes and receptor membrane is a continuous transformative process in cells. Lipid-protein interactions play significant roles in the interaction of donor membranes and receptor membranes.

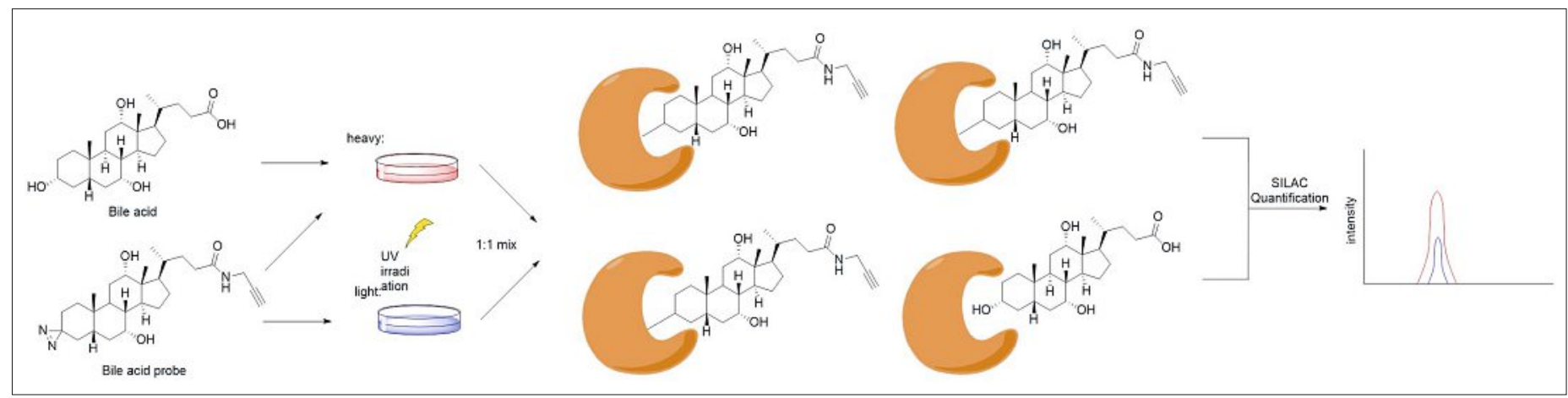

Scheme 17. Investigation of BA-interacting proteins through chemoproteomics. 
Fig. 2. Structures of NSAID-derived photoactivatable probes used in the SIM-PAL study.
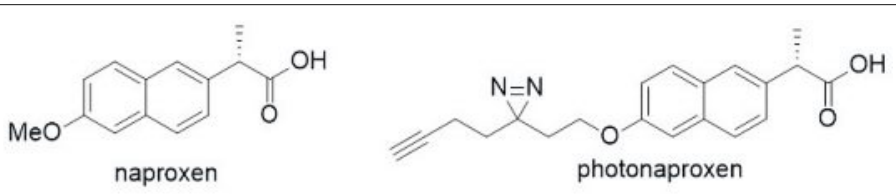

$\mathrm{H}_{2} \mathrm{NO}_{2} \mathrm{~S}$
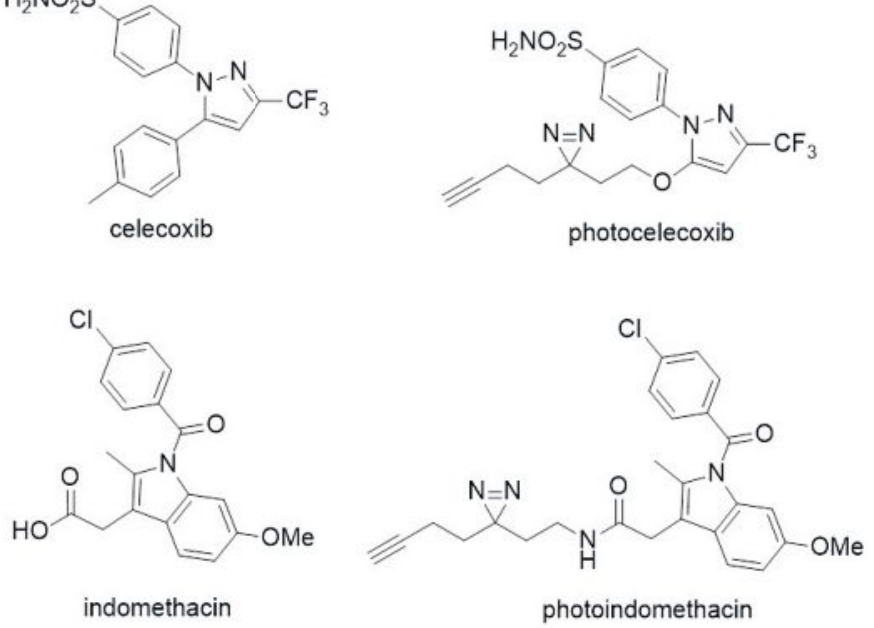<smiles>CCC1CSCC1(C)NC(=O)NC</smiles><smiles>CCC(=O)NCCOCCC(=O)NCC(C)(C)C</smiles>

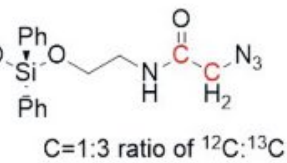

cleavable biotin azide probe

Widely used methods for investigating lipid-protein interaction have to date included: 1) interaction analysis of soluble proteins and lipid molecules with known components; 2) examination of remaining structures of membrane after detergent washing because the remaining structures are considered to be similar to an unmodified original state. ${ }^{[61]}$ In 2000, Huttner and co-workers developed a cholesterol probe containing diazirine group to investigate lipid-protein interactions in mammalian cells $^{[62]}$ (Fig. 3). Diazirine- and 3H-labelled cholesterol was incubated with MDCK cells, and no $3 \mathrm{H}$-labelled compound was detected in cell lysate, indicating that diazirine- and 3H-labelled cholesterol cannot be metabolized by MDCK cells. After elucidating the stability of diazirine-containing cholesterol, this probe was used to explore interactions in MDCK cells and PC12 cells, which identified V-ATPase c, protein synaptotagmin, and protein

synaptophysin as photocholesterol (PC)interacting proteins.

\subsubsection{Fatty Acid Esters of Monogalactosyldiacylgylcerol (MGDG)}

Fatty acid esters of monogalactosyldiacylgylcerol (MGDG) are major constituents of the thylakoid membranes of chloroplasts, and crude extracts of MGDG are known to possesses anti-viral,[63] anti-proliferative, ${ }^{[64]}$ anti-tumor, ${ }^{[65]}$ and anti-inflammatory activities. Dilinolenoyl MGDG has attracted a lot of attention, owing to its anti-inflammatory activity in human peripheral blood neutrophils. To investigate the mode of action of its antiinflammatory activity, Lei and co-workers designed three clickable and photo-reactive probes to identify the dilinolenoyl MGDG-interacting proteins (Fig. 4).[66] They found that if a minimalist linker was installed at the galactosyl moiety, the probe

Fig. 3. Structure of the cholesterol probe.

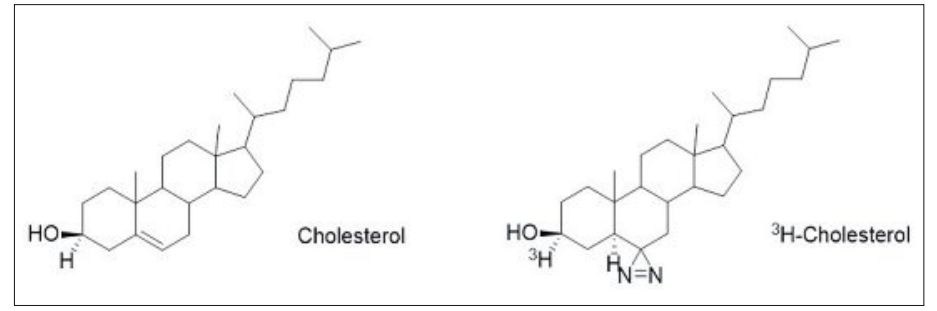

was biologically inactive, suggesting that the galactosyl moiety is essential for recognizing target proteins. After MS and western blot analysis, Toll-like receptor 4 (TLR4) was a potential target. TLR4 can be stimulated by lipopolysaccharide (LPS) binding, which activates downstream signaling pathways and results in the induction of systemic inflammation. A previous structural study showed that LPS can recognize TLR4/MD-2 heterodimers.[67] Eritoran is an analog of LPS that inhibits the binding between TLR4/MD-2, with LPS via insertion into the pocket of MD-2. Further experiments showed that MGDG can outcompete Eritoran for binding with TLR4/MD-2. [68]

\subsubsection{Phosphatidylcholine (PC)}

Phosphatidylcholine (PC) is one of the major components of biological membranes in eukaryotic cells. ${ }^{[69]}$ Besides its role as a cellular building block, PC also participates in posttranslational modifications. ${ }^{[70]}$ In 2017, Yao and co-workers investigated the interaction between PCcontaining diazirine groups with proteins (Scheme 18). A previous investigation suggested that 16-FA and choline are substrates for PC biosynthesis. ${ }^{[71]}$ Introducing alkyne- and diazirine-substituted 16-FA may capture many lipoproteins, which may reduce the signals of real interacting proteins. However, bifunctional choline cannot be utilized to biosynthesize modified PC in A431 cells. After introducing the alkyne-substituted 16-FA and the diazirinesubstituted choline into a culture medium, bifunctional PC probe can be detected after cell lysis. Alkyne group-substituted 16-FA was incubated with A431 cells for $1 \mathrm{~h}$ and diazirine group-substituted choline was then incubated in $16 \mathrm{~h}$, which decreased the production of lapidated protein for global mapping of protein-lipid interactions. In addition, a SILAC strategy was used to reduce the ratio of false positive data. The detected interacting-proteins contains putative lipid-binding proteins such as GAPDH, MTCO2, and StarD7, [72] as well as novel PC-interacting proteins like AIF and PDI. ${ }^{73]}$

\section{Conclusion}

Bioorthogonal reactions have been widely utilized to investigate the function(s) of macromolecules of interest in their native context. Furthermore, photo-induced bioorthogonal reactions offer several advantages over other conventional bioorthogonal reactions, including high spatiotemporal resolution, the lack of a need to use toxic metal catalysts, and the ability to precisely control reactions by modulating light wavelengths and irradiation time. 


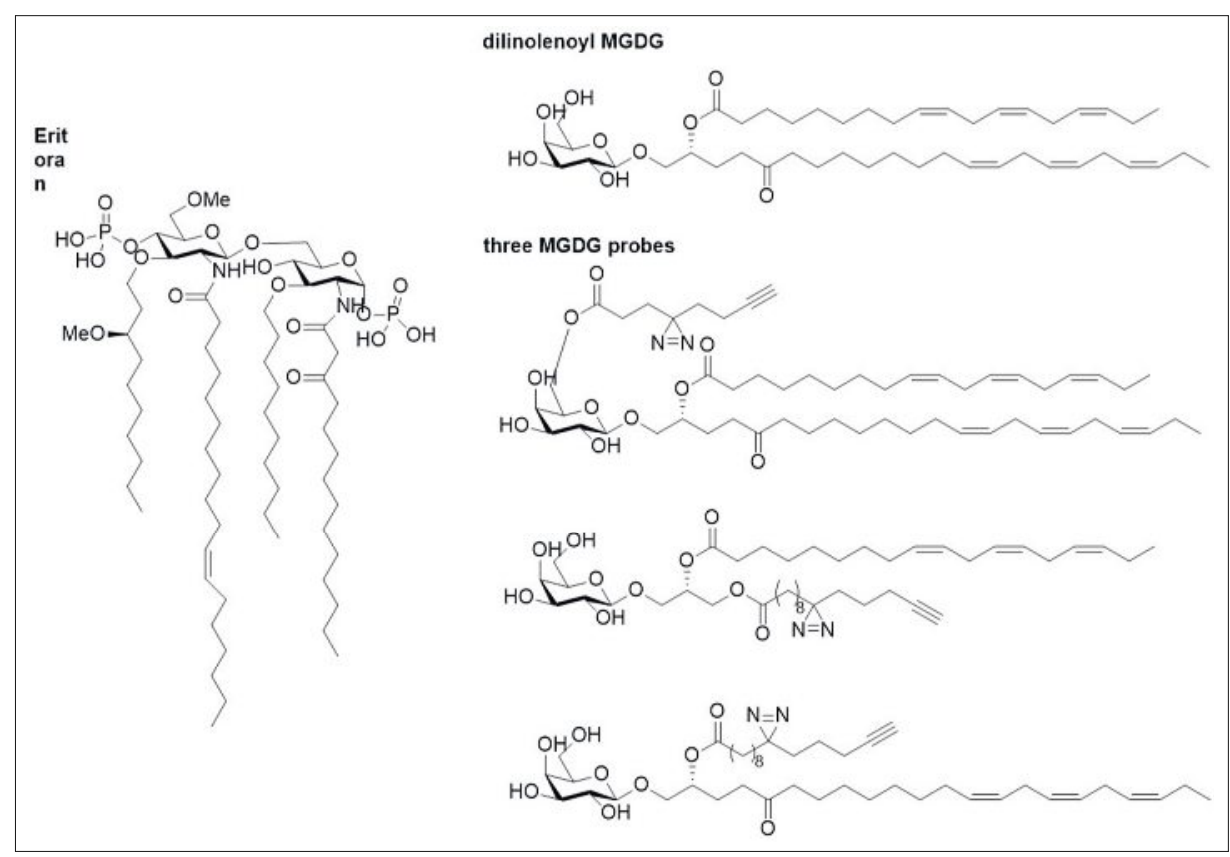

Fig. 4. Structures of the Eritoran, MGDG, and MGDG probes.
Nevertheless, efforts to further improve the orthogonality of these methods, particularly efforts to reduce photo-toxicity, would be greatly welcomed. Understanding the interaction of biomolecules in their native context is significant to elucidate the biological process. Photo-activatable probes have been widely used to characterize interaction among biomolecules and this has provided useful information for elucidating complex biological processes. The future development of additional effective photoactivatable chemical groups will almost certainly heavily feature photoconjugation and will facilitate many future chemical biology studies.

\section{Acknowledgements}

We thank Dr. Hiu Chun Lam (Peking University) for helpful discussions.

\section{Scheme 18.} Phosphatidylcholine probe.
Financial support from the National Key Research and Development Program of China (2017YFA0505200) and the NNSFC (21625201, 21561142002, 21661140001, and 21521003) are gratefully acknowledged.

Received: July 14, 2018

[1] N. J. Agard, J. A. Prescher, C. R. Bertozzi, J. Am. Chem. Soc. 2004, 126, 15046.

[2] X. Ning, J. Guo, M. A. Wolfert, G. J. Boons, Angew. Chem. Int. Ed. 2008, 47, 2253.

[3] A. A. Poloukhtine, N. E. Mbua, M. A. Wolfert, G. J. Boons, V. V. Popik, J. Am. Chem. Soc. 2009, 131, 15769 .

[4] S. Nainar, M. Kubota, C. McNitt, C. Tran, V. V. Popik, R. C. Spitale, J. Am. Chem. Soc. 2017, 139, 8090.

[5] C. D. McNitt, H. Cheng, S. Ullrich, V. V. Popik, M. Bjerknes, J. Am. Chem. Soc. 2017, 139, 14029 . DeForest, K. S. Anseth, C. N. Bowman, Nat. Chem. 2011, 3, 256.

[7] M. D. Hardy, D. Konetski, C. N. Bowman, N. K. Devaraj, Org. Biomol. Chem. 2016, 14, 5555.

[8] M. Bezagu, C. Errico, V. Chaulot-Talmon, F. Monti, M. Tanter, P. Tabeling, J. Cossy, S Arseniyadis, O. Couture, J. Am. Chem. Soc. 2014, 136, 7205.

[9] J. S. Clovis, A. Eckell, R. Huisgen, R. Sustmann, Chem. Ber. 1967, 100, 60.

[10] a) J. Wang, W. Zhang, W. Song, Y. Wang, Z. Yu, J. Li, M. Wu, L. Wang, J. Zang, Q. Lin, J. Am. Chem. Soc. 2010, 132, 14812; b) M. Dietrich, G. Delaittre, J. P. Blinco, A. J. Inglis, M. Bruns, C. Barner-Kowollik, Adv. Funct. Mater. 2012 22, 304.

[11] W. Song, Y. Wang, J. Qu, Q. Lin, J. Am. Chem Soc. 2008, 130, 9654.

[12] W. Song, Y. Wang, J. Qu, M. M. Madden, Q. Lin, Angew. Chem. Int. Ed. 2008, 47, 2832.

[13] W. Song, Y. Wang, Z. Yu, C. I. Vera, J. Qu, Q. Lin, ACS Chem. Biol. 2010, 5, 875 .

[14] M. M. Madden, C. I. Rivera Vera, W. Song, Q. Lin, Chem. Commun. 2009, 5588.

[15] S. Zhao, J. Dai, M. Hu, C. Liu, R. Meng, X. Liu, C. Wang, T. Luo, Chem. Commun. 2016 52, 4702 .

[16] Z. Li, L. Qian, L. Li, J. C. Bernhammer, H. V. Huynh, J. S. Lee, S. Q. Yao, Angew. Chem. Int. Ed. 2016, 55, 2002.

[17] P. An, T. M. Lewandowski, T. G. Erbay, P. Liu, Q. Lin, J. Am. Chem. Soc. 2018, 140, 4860.

[18] C. D. Valentin, M. Freccero, R. Zanaletti, M. Sarzi-Amadè, J. Am. Chem. Soc. 2001, 123 8366.

[19] a) P. Wang, R. Liu, X. Wu, H. Ma, X. Cao, P. Zhou, J. Zhang, X. Weng, X. L. Zhang, J. Qi, X. Zhou, L. Weng, J. Am. Chem. Soc. 2003, 125 , 1116; b) E. E. Weinert, R. Dondi, S. ColloredoMelz, K. N. Frankenfield, C. H. Mitchell, M. Freccero, S. E. Rokita, J. Am. Chem. Soc. 2006 128,11940 .

[20] S. Arumugam, V. V. Popik, J. Am. Chem. Soc 2011, 133, 15730

[21] S. Arumugam, S. V. Orski, J. Locklin, V. V. Popik, J. Am. Chem. Soc. 2012, 134, 179

[22] S. Arumugam, J. Guo, N. E. Mbua, F. Friscourt, N. Lin, E. Nekongo, G. J. Boons, V. V. Popik, Chem. Sci. 2014, 5, 1591.

[23] A. Padwa, J. Smolanoff, J. Am. Chem. Soc. 1971, 93, 548.

[24] R. K. Lim, Q. Lin, Chem. Commun. 2010, 46 , 7993.

[25] a) C. E. Hoyle, C. N. Bowman, Angew. Chem. 2010, 122, 1584; b) C. E. Hoyle, A. B. Lowe, C. N. Bowman, Chem. Soc. Rev. 2010, 39, 1355.

[26] a) A. Dondoni, A. Marra, Chem. Soc. Rev. 2012 41, 573; b) M. Uygun, M. A. Tasdelen, Y. Yagci, Macromol. Chem. Phys. 2010, 211, 103.

[27] Y. Li, M. Yang, Y. Huang, X. Song, L. Liu, P. R. Chen, Chem. Sci. 2012, 3, 2766.

[28] Y. Wang, D. H. Chou, Angew. Chem. Int. Ed. 2015, 54, 10931 .

[29] H. Bader, L. C. Cross, I. Heilbron, E. R. H Jones, J. Chem. Soc. 1949, 619

[30] A. B. Lowe, Polymer 2014, 55, 5517.

[31] A. Dondoni, A. Massi, P. Nanni, A. Roda, Chemistry 2009, 15, 11444.

[32] M. Lo Conte, S. Staderini, A. Marra, M Sanchez-Navarro, B. G. Davis, A. Dondoni, Chem. Commun. 2011, 47, 11086.

[33] Y. Li, M. Pan, Y. Li, Y. Huang, Q. Guo, Org. Biomol. Chem. 2013, 11, 2624

[34] Y. M. Li, M. Y. Yang, Y. C. Huang, Y. T. Li, P. R Chen, L. Liu, ACS Chem. Biol. 2012, 7, 1015.

[35] Y. Tian, J. Li, H. Zhao, X. Zeng, D. Wang, Q Liu, X. Niu, X. Huang, N. Xu, Z. Li, Chem. Sci. 2016, 7, 3325

[36] a) E. Smith, I. Collins, Future Med. Chem. 2015, 7, 159; b) T. Tomohiro, Y. Hatanaka, Heterocycles 2014, 89, 2697. 
[37] Ajaib Singh, Edward R. Thornton, F. H Westheimer, J. Biol. Chem. 1962, 237.

[38] L. Dubinsky, B. P. Krom, M. M. Meijler, Bioorg. Med. Chem. 2011, 20, 554.

[39] J. Sumranjit, S. J. Chung, Molecules 2013, 18, 10425.

[40] J. Das, Chem. Rev. 2011, 111, 4405.

[41] B. Erni, H. G. Khorana, J. Am. Chem. Soc. 1980, 102, 3888 .

[42] Y. Zhang, G. Burdzinski, J. Kubicki, M. S. Platz, J. Am. Chem. Soc. 2008, 130, 16134.

[43] J. S. Teodoro, A. P. Rolo, C. M. Palmeira, Trends Endocrinol. Metab. 2011, 22, 458.

[44] Y. Zhang, F. Y. Lee, G. Barrera, H. Lee, C. Vales, F. J. Gonzalez, T. M. Willson, P. A. Edwards, Proc. Natl. Acad. Sci. USA 2006, 103, 1006.

[45] B. Cariou, K. van Harmelen, D. Duran-Sandoval, T. H. van Dijk, A. Grefhorst, M. Abdelkarim, S. Caron, G. Torpier, J. C. Fruchart, F. J. Gonzalez, F. Kuipers, B. Staels, J. Biol Chem. 2006, 281, 11039.

[46] T. Li, J. Y. Chiang, Pharmacol. Rev. 2014, 66, 948.

[47] M. Makishima, Science 1999, 284, 1362.

[48] M. G. Silveira, K. D. Lindor, Expert Opin. Pharmacother. 2014, 15, 365 .

[49] S. Zhuang, Q. Li, L. Cai, C. Wang, X. Lei, ACS Cent. Sci. 2017, 3, 501.

[50] R. Krattinger, A. Bostrom, S. M. L. Lee, W. E. Thasler, H. B. Schioth, G. A. Kullak-Ublick, J. Mwinyi, Life Sci. 2016, 156, 47.
[51] P. Magotti, I. Bauer, M. Igarashi, M. Babagoli, R. Marotta, D. Piomelli, G. Garau, Structure 2015, 23, 598 .

[52] S. Richter, J. P. Richter, S. Y. Mehta, A. M. Gribble, A. J. Sutherland-Smith, K. M. Stowell, C. G. Print, R. S. Ronimus, W. R. Wilson, Mol. Cell Biochem. 2012, 364, 131.

[53] N. R. Jana, Cell Mol. Life Sci. 2008, 65, 1295.

[54] Y. X. Zhu, K. M. Kortuem, A. K. Stewart, Leuk. Lymphoma 2013, 54, 683.

[55] G. W. Pasternak, Neuropharmacology 2014, 76 Pt B, 198.

[56] J. Gao, A. Mfuh, Y. Amako, C. M. Woo, J. Am Chem. Soc. 2018, 140, 4259.

[57] J. R. Vane, Nature New Biol. 1971, 231, 232

[58] M. J. Yin, Y. Yamamoto, R. B. Gaynor, Nature 1998, 396, 77

[59] C. M. Woo, A. T. Iavarone, D. R. Spiciarich, K. K. Palaniappan, C. R. Bertozzi, Nat. Methods 2015, 12, 561 .

[60] M. Kol, R. Panatala, M. Nordmann, L. Swart, L. van Suijlekom, B. Cabukusta, A. Hilderink, T. Grabietz, J. G. Mina, P. Somerharju, S Korneev, F. G. Tafesse, J. C. Holthuis, J. Lipid Res. 2016, 57, 1273.

61] D. A. Brown, J. K. Rose, Cell 1992, 68, 533

[62] C. Thiele, M. J. Hannah, F. Fahrenholz, W. B. Huttner, Nat. Cell Biol. 2000, 2, 42.

[63] S. Loya, V. Reshef, E. Mizrachi, C. Silberstein, Y. Rachamim, S. Carmeli, A. Hizi, J. Nat. Prod. 1998, 61, 891 .
[64] H. Akasaka, R. Sasaki, K. Yoshida, I. Takayama, T. Yamaguchi, H. Yoshida, Y. Mizushina, Biochim. Biophys. Acta 2013, 1830, 2517.

[65] E. H. Andrianasolo, L. Haramaty, A. Vardi, E. White, R. Lutz, P. Falkowski, J. Nat. Prod. 2008, 71, 1197 .

[66] X. Liu, T. Dong, Y. Zhou, N. Huang, X. Lei, Angew. Chem. 2016, 128, 14542.

[67] B. S. Park, D. H. Song, H. M. Kim, B. S. Choi, H. Lee, J. O. Lee, Nature 2009, 458, 1191.

[68] A. Barochia, S. Solomon, X. Cui, C. Natanson, P. Q. Eichacker, Expert Opin. Drug Metab. Toxicol. 2011, 7, 479.

[69] M. R. Wenk, Cell 2010, 143, 888.

[70] A. Shevchenko, K. Simons, Nat. Rev. Mol. Cell Biol. 2010, 11, 593.

[71] P. Haberkant, R. Raijmakers, M. Wildwater, T. Sachsenheimer, B. Brugger, K. Maeda, M. Houweling, A. C. Gavin, C. Schultz, G. van Meer, A. J. Heck, J. C. Holthuis, Angew. Chem. Int. Ed. 2013, 52, 4033 .

[72] Y. Horibata, H. Sugimoto, J. Biol. Chem. 2010, $285,7358$.

[73] L. Ellgaard, L. W. Ruddock, EMBO Rep. 2005, $6,28$. 